OPEN ACCESS

Edited by:

Teresa Bellon,

University Hospital La Paz Research Institute (IdiPAZ), Spain

Reviewed by:

Maja Mockenhaupt,

University of Freiburg Medical Center, Germany

Chia-Yu Chu,

National Taiwan University Hospital, Taiwan

${ }^{*}$ Correspondence: Mayumi Ueta

mueta@koto.kpu-m.ac.jp

Specialty section: This article was submitted to

Ophthalmology,

a section of the journal

Frontiers in Medicine

Received: 05 January 2021 Accepted: 04 November 2021 Published: 01 December 2021

Citation:

Ueta M (2021) Findings by an International Collaboration on

SJS/TEN With Severe Ocular

Complications. Front. Med. 8:649661.

doi: 10.3389/fmed.2021.649661

\section{Findings by an International Collaboration on SJS/TEN With Severe Ocular Complications}

\author{
Mayumi Ueta* \\ Department of Ophthalmology, Kyoto Prefectural University of Medicine, Kyoto, Japan
}

Stevens-Johnson Syndrome (SJS) is an acute inflammatory vesiculobullous reaction of the skin and mucosa, e.g., the ocular surface, oral cavity, and genitals. In patients with extensive skin detachment and a poor prognosis, the condition is called toxic epidermal necrolysis (TEN). Not all, but some patients with SJS/TEN manifest severe ocular lesions. Approximately $50 \%$ of SJS/TEN patients diagnosed by dermatologists and in burn units suffer from severe ocular complications (SOC) such as severe conjunctivitis with pseudomembrane and ocular surface epithelial defects in the acute stage. In the chronic stage, this results in sequelae such as severe dry eye and visual disturbance. Before 2005, our group of Japanese scientists started focusing on ophthalmic SJS/TEN with SOC. We found that cold medicines were the main causative drugs of SJS/TEN with SOC and that in Japanese patients, HLA-A*02:06 and HLA-B*44:03 were significantly associated with cold medicine-related SJS/TEN with SOC (CM-SJS/TEN with SOC). We expanded our studies and joined scientists from Korea, Brazil, India, Taiwan, Thailand, and the United Kingdom in an international collaboration to detect the genetic predisposition for SJS/TEN with SOC. This collaboration suggested that in Japanese patients, cold medicines, including NSAIDs, were the main causative drugs, and that HLA-A*02:06 was implicated in Japanese and Korean patients and HLA-B*44:03 in Japanese-, Indian-, and European ancestry Brazilian patients. Our joint findings reveal that there are ethnic differences in the HLA types associated with SJS/TEN with SOC.

Keywords: Stevens-Johnson syndrome (SJS), toxic epidermal necrolysis (TEN), severe ocular complications (SOC), HLA, cold medicine

\section{INTRODUCTION}

Stevens-Johnson syndrome (SJS) is an acute inflammatory vesiculobullous reaction of the mucosa of the ocular surface, oral cavity, and genitals, and of the skin. In patients with extensive skin detachment and a poor prognosis, the condition is called toxic epidermal necrolysis (TEN). In the acute stage of SJS/TEN, approximately $50 \%$ of patients present with severe ocular lesions such as severe conjunctivitis with pseudomembrane and ocular surface epithelial defects (1).

Ophthalmologists encounter patients not only in the acute- but also the chronic stage. Dermatologists, on the other hand, tend to see SJS/TEN patients only in the acute stage, although in some countries such as France and Germany dermatologists also followed up the patients long time. Our ophthalmologic diagnosis of SJS/TEN was based on a confirmed history of acute-onset high fever, serious mucocutaneous illness with skin eruptions, and involvement of at least two mucosal sites, including the ocular surface (2-9). SJS/TEN patients with severe ocular complications (SOC) 
in the acute stage often develop sequelae such as vision loss and very severe dry eye that prevent their having a normal life (10).

We defined acute-stage SOC as a condition with severe conjunctivitis with pseudomembrane and epithelial defects on the ocular surface (cornea and/or conjunctiva) (11). Chronicstage SOC was defined as a condition with sequelae such as severe dry eye, trichiasis, symblepharon, and conjunctival invasion into the cornea (Figure 1A) (10). Ophthalmologists tend to diagnose both SIS and TEN with SOC broadly as "ophthalmic SIS" (Figure 1B) (4).

Dermatologists and others reported anticonvulsants such as carbamazepine and allopurinol (a uric acid-lowering drug) as being the main SJS/TEN-inciting drugs (12), while Japanese dermatologists reported that NSAIDs and multi-ingredient cold medications were main causative drugs for SJS/TEN (13). HLA analyses have shown that a genetic predisposition plays a role in the response to disease-eliciting drugs. Carbamazepine-induced SJS/TEN manifested a very strong association with the HLA$B^{*}$ 15:02 allele in Taiwanese Han Chinese patients (14), and the $H L A-A^{*} 31: 01$ allele was strongly associated with carbamazepineinduced SJS/TEN in Japanese- (15) and European patients (16), the HLA-B*57:01 allele was associated with carbamazepineinduced SJS/TEN in European patients (17). Allopurinolinduced SJS/TEN was strongly associated with $H L A-B^{*}$ 58:01

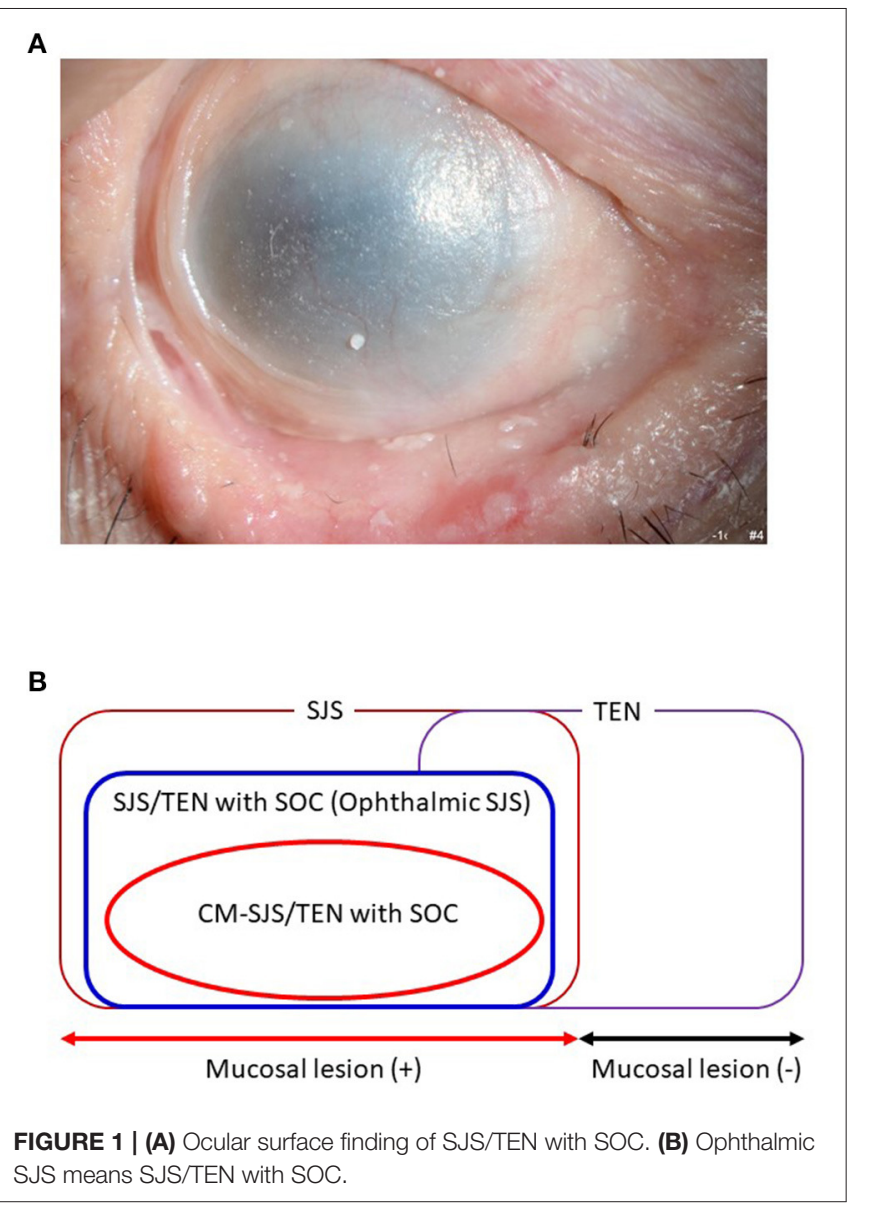

in Han Chinese- (18), European ancestry- (19), and Japanese patients (20). Interestingly, not all patients with carbamazepineinduced SJS/TEN develop SOC (21). Allopurinol has been reported to elicit SIS/TEN without SOC (22).

We reported that about $80 \%$ of SJS/TEN with SOC patients seen at the Kyoto Prefectural University of Medicine developed SJS/TEN within several days after taking cold medicines (we recognized the onset of SJS/TEN when the patients had eruptions.) (8).

These included multi-ingredient cold medications and nonsteroidal anti-inflammatory drugs (NSAIDs) $(2,4,6,8,23)$. Our Brazilian collaborators found that $53 \%$ of their SJS/TEN with SOC patients had taken cold medicines (24) as had $69 \%$ of Thai patients with SJS/TEN with SOC (25), and 50\% of Taiwanese patients (26). Our Korean collaborators suspected that NSAIDs and cold medicines were associated with SOC in their SJS/TEN patients (27). These observations suggest that such medicines are major causative drugs in SJS/TEN with SOC patients of different ethnicities.

This mini-review cites the results of our international collaborative efforts to identify the genetic predisposition for SJS/TEN with SOC.

\section{HLA TYPES ASSOCIATED WITH SJS/TEN WITH SOC}

The extreme rarity of cutaneous and ocular surface reactions to drugs led us to suspect individual susceptibility. Therefore, we entered an international collaboration to analyze the association between HLA genotypes and SJS/TEN with SOC.

\section{Japan}

In 2007, our Japanese group first reported the HLA types associated with SJS/TEN with SOC; the ocular disease was strongly associated with $H L A-A^{*} 02: 06$ [40 patients, 113 controls; odds ratio $(\mathrm{OR})=5.1, p=0.00003$ ] (28). Finding that about $80 \%$ of our Japanese SJS/TEN with SOC patients developed SJS/TEN after taking cold medicines to combat the common cold (8), we started to focus on cold medicine-related SJS/TEN (CM-SJS/TEN) with SOC. We reported that the ocular disease was strongly associated with $H L A-A^{*} 02: 06$ [151 patients, 639 controls; $\left.\left(\mathrm{OR}=5.6, p=2.7 \times 10^{-20}\right)\right]$ and significantly associated with $H L A-B^{*} 44: 03$ [151 patients, 639 controls; OR $=2.0, p=1.3 \times 10^{-3}$ ] (2). These HLA genotypes were not associated with cold medicine-unrelated, i.e., other medicinerelated SJS/TEN with SOC (2). This suggested that the associated HLA genotypes were different and depended on the causative $\operatorname{drug}(\mathrm{s})(2,4,29)$. Moreover, $H L A-A^{*} 02: 06$ and $H L A-B^{*} 44: 03$ were not associated with CM-SJS/TEN without SOC (2), suggesting that different HLA genotypes were involved in the development of SJS/TEN with- and without SOC (2).

We reported that the main causative drugs for SJS/TEN with SOC in Japanese patients were cold medicines, including multiingredient cold medications and NSAIDs taken to combat the common cold. As we also found that acetaminophen, present in various cold medicines, was the most frequently implicated 
causative drug $(2,30)$, we focused on acetaminophen-related SJS/TEN with SOC. Analysis of the involved HLA types revealed that $H L A-A^{*} 02: 06$ was strongly associated with_acetaminophenrelated SJS/TEN with SOC [80 patients, 113 controls; OR $=5.4$, $\left.p=8.0 \times 10^{-7}\right](30)$.

\section{Korea}

Together with our Korean collaborators we investigated the HLA types ( $H L A-A^{*} 02: 06$ and $\left.H L A-B^{*} 44: 03\right)$ that were associated with CM-SJS/TEN with SOC in Japanese patients. We compared ours with samples from Korean patients and found that in Koreans, CM-SJS/TEN with SOC was also significantly associated with $H L A-A^{*} 02: 06$ (31 patients, 90 controls; $\mathrm{OR}=3.0, p=0.018$ ), but not with $H L A-B^{*} 44: 03$ (3).

Our Korean collaborators suspected that NSAIDs and cold medicines were associated with SOC in Korean patients with SJS/TEN (27). They reported that allopurinol-induced SJS/TEN might not elicit serious acute or chronic complications of the ocular surface (22).

They then focused on Korean CM-SJS/TEN with SOC and investigated all of $H L A$-class I (HLA-A, HLA-B, HLA-C). In their patients they identified $H L A-A^{*} 02: 06$ (40 patients, 120 controls; $\mathrm{OR}=3.0, p=0.0083$ ) and $H L A-C^{*} 03: 04$ (40 patients, 120 controls; $\mathrm{OR}=3.5, p=0.010$ ) as potential positive markers for CM-SJS/TEN with SOC, and $H L A-C^{*} 03: 03$ (40 patients, 120 controls; $\mathrm{OR}=0.10, p=0.0056$ ) as a possible indicator of protection against CM-SJS/TEN with SOC in the Korean population (31).

\section{Brazil}

Together with our Brazilian collaborators we investigated the HLA types (HLA-A*02:06 and $\left.H L A-B^{*} 44: 03\right)$ that were associated with Japanese CM-SJS/TEN with SOC. Comparison of our and Brazilian samples revealed that in Brazilian CM-SJS/TEN with SOC, there was a significant association with $H L A-B^{*} 44: 03$ (39 patients, 134 controls; $\mathrm{OR}=2.7, p=0.024$ ), but not with $H L A-A^{*} 02: 06$, a genotype not found in all Brazilian population (3). Interestingly, focused on European ancestry of Brazilians, the association with $H L A-B^{*} 44: 03$ was stronger (15 patients, 62 controls; $\mathrm{OR}=6.2, p=0.0037$ ) than in all Brazilians (3).

As the Brazilian collaborators found that $53 \%$ of their SJS/TEN with SOC patients had taken cold medicines before disease onset (24), they investigated the associated HLA types of CM-SJS/TEN with SOCs. Their studies suggested $H L A-A^{*} 66: 01$ as a potential marker for CM-SJS/TEN with SOCs in Brazilians (39 patients, 133 controls; $\mathrm{OR}=24.0, p<0.001$ ) of both Pardo- (19 patients, 66 controls; $\mathrm{OR}=12.2, p=0.03)$ and European ancestry $(16$ patients, 61 controls; $\mathrm{OR}=21.2, p=0.04)$ and that $H L A-B^{*} 44: 03$ ( 16 patients, 61 controls; $\mathrm{OR}=5.50, p=0.01$ ) and $H L A-C^{*} 12: 03$ (16 patients, 61 controls; $\mathrm{OR}=8.79, p=0.008$ ) might be markers only in individuals of European ancestry. Moreover, they stated that $H L A-A^{*} 11: 01$ (39 patients, 133 controls; OR $=0.074, p=$ 0.008 ) might be a marker of resistance to CM-SJS/TEN with SOC (24).

Because Dipyrone was broadly used as cold medicine in Brazil, we also focused on dipyrone-related SJS/TEN with SOCs and found that $H L A-B^{*} 44: 03$ (carrier frequency: $p=0.002, \mathrm{Pc}=0.02$,
$\mathrm{OR}=8.8$; gene frequency: $p=0.001, \mathrm{Pc}=0.01, \mathrm{OR}=7.5)$ and $H L A-D Q B 1^{*} 04: 02$ (gene frequency: $p=0.003, \mathrm{Pc}=0.03, \mathrm{OR}=$ 12.6) were significantly associated with cases of dipyrone-related SJS/TEN with SOCs in the Brazilian population of European ancestry, and that $H L A-C^{*} 05: 01$ (carrier frequency: $p=0.001, \mathrm{Pc}$ $=0.01, \mathrm{OR}=9.4$; gene frequency: $p=0.002, \mathrm{Pc}=0.02, \mathrm{OR}=$ 15.0) was significantly associated with cases of dipyrone-related SJS/TEN with SOCs in the Brazilian population of mixed raced ancestry (32).

\section{India}

Together with our Indian collaborators we investigated the HLA types (HLA- $A^{*} 02: 06$ and $\left.H L A-B^{*} 44: 03\right)$ associated with Japanese CM-SJS/TEN with SOC.

In samples from Indian patients with CM-SJS/TEN with SOC there was a significant association with $H L A-B^{*} 44: 03$ (20 patients, 55 controls; $\mathrm{OR}=12.3, p=1.1 \times 10^{-5}$ ), but not with $H L A-A^{*} 02: 06$ (3). Although the number of Indian patients was small, the association between Indian CM-SJS/TEN with SOC and $H L A-B^{*} 44: 03$ was strong and significant (3).

According to Kannabiran et al. (33), Indian ophthalmologists found it difficult to obtain a detailed history of disease onset from their SJS/TEN with SOC patients and in many patients they could not identify causative drugs. HLA analysis showed that $H L A-A^{*} 33: 03$ (80 patients, 50 controls; OR $=3.4, p=2.7$ $\left.\times 10^{-3}\right), H L A-B^{*} 44: 03$ (80 patients, 50 controls; OR $=12.2$, $\left.p=7.3 \times 10^{-9}\right)$, and $H L A-C^{*} 07: 01$ (80 patients, 50 controls; $\left.\mathrm{OR}=6.5, p=4.4 \times 10^{-6}\right)$ were risk alleles. HLA-B ${ }^{*}$ 57:01 (80 patients, 50 controls; $\left.\mathrm{OR}=0.05, p=3.0 \times 10^{-4}\right)$ and HLA$C^{*} 06: 02$ (80 patients, 50 controls; $\mathrm{OR}=0.1, p=4.0 \times 10^{-4}$ ) were protective alleles in the Indian population. Haplotypes comprised of $H L A-B^{*} 44: 03$ and $H L A-C^{*}$ 07:01 were strongly associated with SJS/TEN with SOC in the Indian population (80 patients, 50 controls; OR $\left.=11.0, p=1.1 \times 10^{-7}\right)(33)$.

\section{Thailand}

Together with our Thai collaborators we investigated causative drugs in their SJS/TEN with SOC patients and performed HLA analysis using Thai samples. $H L A-A^{*} 33: 03$ (71 patients, 159 controls; OR $=2.6, p=0.0028), H L A-B^{*} 44: 03$ (71 patients, 159 controls; $\mathrm{OR}=6.0, p<0.0001$ ), and $H L A-C^{*} 07: 01$ (71 patients, 159 controls; $\mathrm{OR}=4.9, p<0.0001$ ) exhibited a significant associations with SJS/TEN with SOC (25). Among 71 Thai SJS/TEN with SOC patients, 49 (69\%) had a history of taking cold medications prior to SJS/TEN onset.

A focus on CM-SJS/TEN with SOC revealed that HLA$B^{*} 44: 03$ (49 patients, 159 controls; $\mathrm{OR}=7.2, p<0.0001$ ) and $H L A-C^{*}$ 07:01 (49 patients, 159 controls; OR $=6.1, p<0.0001$ ) were significantly associated with Thai CM-SJS/TEN with SOC. In 17 of 49 patients with CM-SJS/TEN with SOC (34.7\%), a haplotype comprised of $H L A-B^{*} 44: 03$ and $H L A-C^{*} 07: 01$ was present. This was the case in only 11 of 159 controls (6.9\%) (OR $\left.=7.1, p=5.5 \times 10^{-6}\right)$, suggesting that the HLA- $B^{*} 44: 03-H L A-$ $C^{*}$ 07:01 haplotype was a potential risk factor for CM-SJS/TEN with SOC in the Thai population (25).

In Thailand, as in the USA and UK, cold medicines, especially acetaminophen (paracetamol), are widely-used over-the-counter 
drugs. Elsewhere we reported that in Japan, acetaminophen is the most frequently included drug in various cold medicines (2, 30). Therefore, we focused on Japanese acetaminophen-related SJS/TEN with SOC and analyzed the HLA types (30). Together with our Thai collaborators we also investigated Thai patients with acetaminophen-related SJS/TEN with SOC and analyzed the HLA types. Jongkhajornpong et al. (34) reported a significant association with $H L A-A^{*} 33: 03$ (20 patients, 60 controls; OR = 5.4, $p=0.0030$ ), HLA- $B^{*} 44: 03$ (20 patients, 60 controls; OR $=9.0, p=0.0004)$, HLA-C $C^{*} 07: 01$ (20 patients, 60 controls; $\mathrm{OR}=9.3, p=0.0002)$, and the $H L A-B^{*} 44: 03-H L A-C^{*} 07: 01$ haplotype (20 patients, 60 controls; $\mathrm{OR}=9.0, p<0.001)$ in Thai patients with acetaminophen-related SJS/TEN with SOC, suggesting that they may have a role in the pathogenesis of SOC in acetaminophen-related SJS/TEN.

\section{Taiwan}

Our Taiwanese collaborators found that the main causative drugs in 26 Han Chinese with SJS/TEN with SOC were cold medicines; in 13 of 26 patients with SOC, cold medicines were the causative drugs, in none of 7 patients without SOC they identified cold medications as causative (26). Their findings echoed earlier studies that implicated cold medicines in the development of SOC in $80 \%$ of Japanese SJS/TEN patients (2, 35), 53\% of Brazilian patients (24), and $69 \%$ of Thai patients (25).

Together with our Taiwanese collaborators we performed HLA analysis of SJS/TEN with SOC in the Han Chinese and found that $H L A-A^{*} 02: 07$ (26 patients, 98 controls; $\mathrm{OR}=3.2, p$ $=0.049$ ) was associated with their development of the disease. Our focus on CM-SJS/TEN with SOC revealed that HLA-A* 02:07 (13 patients, 98 controls; $\mathrm{OR}=5.6, p=0.016$ ) was strongly associated with the development of SOC among Han Chinese CM-SJS/TEN patients (26). Single amino acid substitutions in major histocompatibility complex (MHC) class I molecules were found to play a role in distinct peptide repertoires. For example, three $H L A-A 2$ subtypes, i.e., $H L A-A^{*} 02: 04, H L A-A^{*} 02: 06$, and $H L A-A^{*} 02: 07$, differed by only a single amino acid residue substitution; each harbored the $H L A-A^{*} 02: 01$ molecule at the floor of their binding grooves. Allele-specific peptide motifs for each HLA-A2 subtype differed substantially from the HLA$A^{*}$ 02:01 motif in the dominant anchor residues (36). Although the carrier- and gene frequency of $H L A-A^{*} 02: 06$ in Japanese patients with CM-SJS/TEN with SOCs was significantly higher than in the control group, the frequency of $H L A-A^{*} 02: 07$ was similar in both groups (2). We found that the expression of $H L A-A^{*} 02: 07$ but not of $H L A-A^{*} 02: 06$ was associated with CMSJS/TEN with SOC in the Han Chinese patients (26).

No HLA- $B^{*}$ 44:03 expression was detected in Han Chinese SJS/TEN patients or the controls (26), a finding compatible with earlier studies that showed that only $0.41-0.63 \%$ of the Taiwanese Han Chinese population harbored $H L A-B^{*} 44: 03$ (37, 38). This observation suggests a genetic diversity in the pathogenesis of SJS among different ethnic groups although, because the number of samples was small, these studies must be expanded to include more samples.

\section{United Kingdom}

Our UK collaborators found that 9 of their 28 patients with SJS/TEN with SOC (32\%) had taken cold medicines (39). Together with our UK collaborators we analyzed the association of HLA-A, HLA-B, and HLA-C alleles with SJS/TEN in 33 patients residing in the UK (28 patients with- and 5 without SOC) and in age-matched controls. There was a statistically significant and novel negative allele association with $H L A-B^{*} 07: 02$ (25 patients, 15 controls; $\mathrm{OR}=0.16, p=0.012)$ and with $H L A-C^{*} 07: 02(25$ patients, 15 controls; $\mathrm{OR}=0.09, p=0.030$ ) in a sub-group of European ancestry SJS/TEN patients (both with and without SOC) but not in their controls. This finding identified these alleles as being protective (39). Interestingly, a focus on European ancestry patients with SJS/TEN with SOC revealed only the association with $H L A-B^{*} 07: 02$ (23 patients, 15 controls; OR = $0.17, p=0.027)$, but not with $H L A-C^{*} 07: 02$. When the focus was directed on European ancestry patients with CM-SJS/TEN with SOC, both associations with $H L A-B^{*} 07: 02$ and $H L A-C^{*} 07: 02$ disappeared (39). Thus, although $H L A-B^{*} 07: 02$ was associated with SJS/TEN with SOC in European ancestry, it may not be a biomarker for CM-SJS/TEN with SOC in that population. Because the number of samples was small, these studies must be expanded to include more samples.

\section{DISCUSSION}

A summary of our collaborative HLA analyses is shown in Table 1. It shows that $H L A-B^{*} 44: 03$ was significantly associated with CM-SJS/TEN with SOC in the Japanese (2), in Brazilians, especially European ancestry Brazilians $(3,24,32)$, in Indian patients $(3,33)$, and in Thais $(25,34)$. HLA-A*02:06 was significantly associated with CM-SJS/TEN with SOC in the Japanese (2) and in Koreans (3, 31). Ma et al. (26) suggested that $H L A-A^{*} 02: 07$, differing by only a single amino acid residue substitution from $H L A-A^{*} 02: 06$, might be significantly associated with CM-SJS/TEN with SOC in Taiwanese patients.

The acetaminophen-associated HLA type might be a little different between CM-SJS/TEN with SOC in Japanese- (HLA$\mathrm{A}^{*}$ 02:06) (30) and Thai patients (HLA-B*44:03-HLA-C*07:01 haplotype) (34). Moreover, the dipyrone-associated HLA types for CM-SJS/TEN with SOC in the Brazilian population were $H L A-B^{*} 44: 03$ and $H L A-D Q B 1^{*} 04: 02$ in European ancestry, and $H L A-C^{*}$ 05:01 in mixed raced ancestry (32).

We think that a common function of cold medicines such as acetaminophen, dipyrone, and NSAIDs is highly implicated in the onset of SJS/TEN with SOC $(4,23,30,40)$.

The common function of cold medicines is the suppression of prostaglandin $\mathrm{E}_{2}\left(\mathrm{PGE}_{2}\right)$ production which suppress mucocutaneous inflammation. $\mathrm{PGE}_{2}$ acts on $\mathrm{EP} 3\left(\mathrm{PGE}_{2}\right.$ receptor 3 ) in the epidermis (41) and the mucosal epithelium $(42,43)$ and negatively regulates mucocutaneous inflammation. We suspect that cold medicines that include acetaminophen and dipyrone could upregulate inflammatory responses by suppressing the production of $\mathrm{PGE}_{2}$ which suppress mucocutaneous inflammation, that they augment abnormal immune responses, 
TABLE 1 | Carrier frequencies of each country.

\begin{tabular}{|c|c|c|c|c|c|c|c|c|c|c|c|c|c|}
\hline \multirow[t]{2}{*}{ Country } & \multirow{2}{*}{$\begin{array}{l}\text { Ratio of } \\
\text { CM-SJS/TEN } \\
\text { with SOC } \\
\text { /SJS/TEN with } \\
\text { SOC }\end{array}$} & \multicolumn{4}{|c|}{ CM-SJS/TEN with SOC } & \multicolumn{4}{|c|}{ SJS/TEN with SOC } & \multicolumn{4}{|c|}{ Acetaminophen-SJS/TEN with SOC } \\
\hline & & $\begin{array}{l}\text { Number of } \\
\text { cases }\end{array}$ & HLA-A & HLA-B & HLA-C & $\begin{array}{l}\text { Number of } \\
\text { cases }\end{array}$ & HLA-A & HLA-B & HLA-C & $\begin{array}{l}\text { Number of } \\
\text { cases }\end{array}$ & HLA-A & HLA-B & HLA-C \\
\hline \multirow[t]{3}{*}{ JAPAN } & \multirow[t]{3}{*}{\begin{tabular}{|l}
$76.0 \%(76 / 100)(4)$ \\
$68.6 \%(151 / 220)$ \\
$(6)$
\end{tabular}} & \multirow[t]{3}{*}{$\begin{array}{l}151 \text { cases vs. } \\
639 \text { controls } \\
{[2014(6)]}\end{array}$} & \multirow[t]{3}{*}{$\mid \begin{array}{l}\text { HLA-A } \text { A }^{*} 2: 06 \\
\mathrm{OR}=5.6 \\
p=2.7 \times 10^{-20}\end{array}$} & \multirow[t]{3}{*}{$\mid \begin{array}{l}\text { HLA-B*44:03 } \\
\mathrm{OR}=2.0 \\
p=1.3 \times 10^{-3}\end{array}$} & & \multirow{3}{*}{$\begin{array}{l}40 \text { cases vs. } 113 \\
\text { controls [2007 (3)] }\end{array}$} & $\begin{array}{l}\text { HLA-A } A^{*} 02: 06 \\
\text { OR }=5.1 \\
p=0.00003\end{array}$ & & & \multirow[t]{3}{*}{$\mid \begin{array}{l}80 \text { cases vs. } 639 \\
\text { controls [2020 } \\
(26)]\end{array}$} & \multirow[t]{3}{*}{$\begin{array}{l}\text { HLA-A }{ }^{*} 02: 06 \\
\mathrm{OR}=6.0 \\
p=4.7 \times 10^{-12}\end{array}$} & $\begin{array}{l}\text { HLA-B*13:01 } \\
\text { OR=4.1 } \\
p=2.0 \times 10^{-3}\end{array}$ & \multirow[t]{3}{*}{$\begin{array}{l}\text { HLA-C } C^{\star} 14: 03 \\
\text { OR }=2.3 \\
p=3.4 \times 10^{-3}\end{array}$} \\
\hline & & & & & & & HLA-A*11:01 & & & & & HLA-B*44:03 & \\
\hline & & & & & & & $\begin{array}{l}\mathrm{OR}=0.1 \\
p=0.0076\end{array}$ & & & & & $\begin{array}{l}\mathrm{OR}=2.4 \\
p=2.1 \times 10^{-3}\end{array}$ & \\
\hline KOREA & \begin{tabular}{|l} 
Not \\
reported [NSAIDs, \\
including cold \\
medicine, might be \\
associated with \\
SOC in Korean \\
patients with \\
SJS/TEN (24)]
\end{tabular} & $\begin{array}{l}40 \text { cases vs. } \\
120 \text { controls } \\
(27)\end{array}$ & $\begin{array}{l}\text { HLA-A*02:06 } \\
\mathrm{OR}=3.0 \\
p=0.0083\end{array}$ & & $\begin{array}{l}\text { HLA-C } C^{*} 03: 03 \\
\mathrm{OR}=0.10 \\
p=0.0056 \\
\text { HLA-C*03:04 } \\
\mathrm{OR}=3.5 \\
p=0.010\end{array}$ & & & & & & & & \\
\hline \multirow[t]{3}{*}{ BRAZIL } & \multirow[t]{3}{*}{$52.7 \%(39 / 74)(22)$} & $\begin{array}{l}74 \text { cases vs. } \\
133 \text { controls } \\
(22)\end{array}$ & $\begin{array}{l}\text { HLA-A*11:01 } \\
\mathrm{OR}=0.074 \\
p=0.008 \\
\mathrm{H} L \mathrm{~A}-\mathrm{A}^{\star} 66: 01 \\
\mathrm{OR}=24.0 \\
p<0.001\end{array}$ & $\begin{array}{l}\text { HLA-B*44:03 } \\
\text { OR }=2.7 \\
p=0.04\end{array}$ & $\begin{array}{l}\text { HLA-C*12:03 } \\
\text { OR }=5.6 \\
p=0.006\end{array}$ & & & & & & & & \\
\hline & & \begin{tabular}{|l|}
19 Pardo \\
cases vs. 66 \\
Pardo controls \\
$(22)$ \\
\end{tabular} & $\begin{array}{l}\text { HLA-A*66:01 } \\
\text { OR }=12.2 \\
p=0.03\end{array}$ & & & & & & & & & & \\
\hline & & $\begin{array}{l}16 \text { European } \\
\text { cases vs. } 61 \\
\text { European } \\
\text { controls (22) }\end{array}$ & $\begin{array}{l}\text { HLA-A } A^{\star} 66: 01 \\
\mathrm{OR}=21.2 \\
p=0.04\end{array}$ & $\begin{array}{l}\text { HLA-B } B^{\star} 44: 03 \\
\text { OR }=5.5 \\
p=0.01\end{array}$ & $\begin{array}{l}\text { HLA-C*12:03 } \\
\text { OR }=8.8 \\
p=0.008\end{array}$ & & & & & & & & \\
\hline \multirow[t]{4}{*}{ INDIA } & \multirow{4}{*}{$\begin{array}{l}\text { Unknown because } \\
\text { many patients have } \\
\text { no detail memories }\end{array}$} & \multirow{4}{*}{\begin{tabular}{|l|}
20 cases vs. \\
55 controls(ref) \\
(only focused \\
on \\
HLA-A*02:06 \\
and $\left.B^{*} 44: 03\right)$ \\
$(7)$
\end{tabular}} & & HLA-B*4 $44: 03$ & & \multirow{4}{*}{$\begin{array}{l}80 \text { cases vs. } 50 \\
\text { controls (28) }\end{array}$} & HLA-A*33:03 & HLA-B*44:03 & HLA-C*06:02 & & & & \\
\hline & & & & $\begin{array}{l}\mathrm{OR}=12.3 \\
p=1.1 \times 10^{-5}\end{array}$ & & & $\begin{array}{l}\mathrm{OR}=3.4 p=2.7 \\
\times 10^{-3}\end{array}$ & $\begin{array}{l}\mathrm{OR}=12.2 \\
p=7.3 \times 10^{-9}\end{array}$ & $\begin{array}{l}\mathrm{OR}=0.1 \\
p=4.0 \times 10^{-4}\end{array}$ & & & & \\
\hline & & & & & & & & HLA-B`57:01 & HLA-C*07:01 & & & & \\
\hline & & & & & & & & $\begin{array}{l}\mathrm{OR}=0.05 \\
p=3.0 \times 10^{-4}\end{array}$ & $\begin{array}{l}\mathrm{OR}=6.5 \\
p=4.4 \times 10^{-6}\end{array}$ & & & & \\
\hline \multirow[t]{3}{*}{ THAILAND } & \multirow[t]{3}{*}{$69.0 \%(49 / 71)(23)$} & \multirow[t]{3}{*}{$\begin{array}{l}49 \text { cases vs. } \\
159 \text { controls } \\
(23)\end{array}$} & & \multirow[t]{3}{*}{$\begin{array}{l}\text { HLA-B*44:03 } \\
\text { OR }=7.2 \\
p<0.0001\end{array}$} & \multirow[t]{3}{*}{$\begin{array}{l}\text { HLA-C*07:01 } \\
\text { OR }=6.1 \\
p<0.0001\end{array}$} & \multirow[t]{3}{*}{$\begin{array}{l}71 \text { cases vs. } 159 \\
\text { controls (23) }\end{array}$} & $\begin{array}{l}\text { HLA-A*33:03 } \\
\text { OR }=2.6 \\
p=0.0028\end{array}$ & $\begin{array}{l}\text { HLA-B } 27: 04 \\
\text { OR }=0.065 \\
p=0.0066\end{array}$ & $\begin{array}{l}\text { HLA-C*07:01 } \\
\text { OR }=4.9 \\
p<0.0001\end{array}$ & \multirow[t]{3}{*}{$\begin{array}{l}20 \text { cases vs. } 60 \\
\text { controls (29) }\end{array}$} & \multirow[t]{3}{*}{$\begin{array}{l}\text { HLA-A } A^{*} 33: 03 \\
\mathrm{OR}=5.4 \\
p=0.0030\end{array}$} & \multirow[t]{3}{*}{$\begin{array}{l}\text { HLA-B*44:03 } \\
\text { OR }=9.0 \\
p=0.0004\end{array}$} & \multirow[t]{3}{*}{$\begin{array}{l}\text { HLA-C*07:01 } \\
\text { OR }=9.3 \\
p=0.0002\end{array}$} \\
\hline & & & & & & & & HLA-B*44:03 & HLA-C*12:02 & & & & \\
\hline & & & & & & & & $\begin{array}{l}\mathrm{OR}=6.0 \\
p<0.0001\end{array}$ & $\begin{array}{l}\mathrm{OR}=0.11 \\
p=0.0093\end{array}$ & & & & \\
\hline TAIWAN & $50.0 \%$ (13/26) (26) & $\mid \begin{array}{l}13 \text { cases vs } 98 \\
\text { controls (26) }\end{array}$ & $\begin{array}{l}\text { HLA-A*02:07 } \\
\mathrm{OR}=5.6 \\
p=0.016\end{array}$ & & & \begin{tabular}{|l}
26 cases vs. 98 \\
controls (26)
\end{tabular} & $\begin{array}{l}\text { HLA-A*02:07 } \\
\text { OR }=3.2 \\
p=0.049\end{array}$ & & & & & & \\
\hline $\begin{array}{l}\text { UK (White } \\
\text { only) }\end{array}$ & $39.1 \%(9 / 23)(39)$ & $\begin{array}{l}9 \text { cases vs } 15 \\
\text { controls (39) }\end{array}$ & & $\begin{array}{l}(\text { HLA-B*07:02) } \\
\text { Not significant } \\
p=0.23\end{array}$ & & $\begin{array}{l}23 \text { cases vs. } 15 \\
\text { controls (39) }\end{array}$ & & $\begin{array}{l}\text { HLA-B*07:02 } \\
\text { OR }=0.17 \\
p=0.027\end{array}$ & & & & & \\
\hline
\end{tabular}


and that they elicit the induction of SJS/TEN with SOC $(4,23,30,40)$.

Besides HLA types, we investigated other SJS/TEN with SOC susceptibility genes. Our genome-wide association study revealed IKZF1 to be a susceptibility gene for CM-SJS/TEN with SOC in Japanese-, Korean-, and Indian populations (6). It was also significantly associated with CM-SJS/TEN with SOC in Thai patients (44). Consequently, IKZF1 may be a universal marker for CM-SJS/TEN with SOC $(6,44)$. Elsewhere (45) we documented that $I K Z F 1$ regulates mucocutaneous inflammation. We reported that $I K Z F 1$ transgenic mice developed spontaneous mucocutaneous inflammations such as ocular surface- and oral inflammation and dermatitis (45).

In the Japanese population we identified PTGER3 as a susceptibility gene for CM-SJS/TEN with SOC (8), and we reported that $H L A-A^{*} 02: 06$ and PTGER3 polymorphisms exerted additive effects in Japanese and Korean patients with CMSJS/TEN with SOC (OR $=10.8$ and 14.2, respectively) (46).

We also suggest that in addition to microbial infections and cold medicines, the combination of multiple gene polymorphisms and their interactions contributes strongly

\section{REFERENCES}

1. Sotozono C, Ueta M, Nakatani E, Kitami A, Watanabe H, Sueki H, et al. Predictive factors associated with acute ocular involvement in StevensJohnson syndrome and toxic epidermal necrolysis. Am J Ophthalmol. (2015) 160:228-37 e2. doi: 10.1016/j.ajo.2015.05.002

2. Ueta M, Kaniwa N, Sotozono C, Tokunaga K, Saito Y, Sawai H, et al. Independent strong association of HLA-A*02:06 and HLA-B*44:03 with cold medicine-related Stevens-Johnson syndrome with severe mucosal involvement. Sci Rep. (2014) 4:4862. doi: 10.1038/srep04862

3. Ueta M, Kannabiran C, Wakamatsu TH, Kim MK, Yoon KC, Seo KY, et al. Trans-ethnic study confirmed independent associations of HLA$A^{*}$ 02:06 and HLA-B*44:03 with cold medicine-related Stevens-Johnson syndrome with severe ocular surface complications. Sci Rep. (2014) 4:5981. doi: 10.1038/srep05981

4. Ueta M, Kinoshita S. Ocular surface inflammation is regulated by innate immunity. Prog Retin Eye Res. (2012) 31:551-75. doi: 10.1016/j.preteyeres.2012.05.003

5. Ueta M, Sawai H, Shingaki R, Kawai Y, Sotozono C, Kojima K, et al. Genome-wide association study using the ethnicity-specific Japonica array: identification of new susceptibility loci for cold medicine-related StevensJohnson syndrome with severe ocular complications. J Hum Genet. (2017) 62:485-9. doi: 10.1038/jhg.2016.160

6. Ueta M, Sawai H, Sotozono C, Hitomi Y, Kaniwa N, Kim MK, et al. IKZF1, a new susceptibility gene for cold medicine-related Stevens-Johnson syndrome/toxic epidermal necrolysis with severe mucosal involvement. J Allergy Clin Immunol. (2015) 135:1538-45 e17. doi: 10.1016/j.jaci.2014.12.1916

7. Ueta M, Sotozono C, Inatomi T, Kojima K, Tashiro K, Hamuro J, et al. Toll-like receptor 3 gene polymorphisms in Japanese patients with Stevens-Johnson syndrome. Br J Ophthalmol. (2007) 91:962-5. doi: 10.1136/bjo.2006.113449

8. Ueta M, Sotozono C, Nakano M, Taniguchi T, Yagi T, Tokuda Y, et al. Association between prostaglandin E receptor 3 polymorphisms and StevensJohnson syndrome identified by means of a genome-wide association study. $J$ Allergy Clin Immunol. (2010) 126:1218-25 e10. doi: 10.1016/j.jaci.2010.08.007

9. Ueta M, Sotozono C, Tokunaga K, Yabe T, Kinoshita S. Strong association between HLA-A*0206 and Stevens-Johnson syndrome in the Japanese. Am J Ophthalmol. (2007) 143:367-8. doi: 10.1016/j.ajo.2006.09.029

10. Sotozono C, Ang LP, Koizumi N, Higashihara H, Ueta M, Inatomi T, et al. New grading system for the evaluation of chronic ocular manifestations in to the onset of CM-SJS/TEN with SOC. Abnormal Innate Immunity might strongly contribute the pathology of SJS/TEN with $\operatorname{SOC}(4,23)$.

Despite the genetic diversity in SJS/TEN with SOC among different ethnic groups, to prevent its onset and to reduce the incidence of blindness due to SJS/TEN, efforts must continue to identify the genetic predisposition for SJS/TEN with SOC.

\section{AUTHOR CONTRIBUTIONS}

MU wrote this mini review.

\section{FUNDING}

This work was supported by grants-in-aid from the Ministry of Education, Culture, Sports, Science and Technology of the Japanese government, by the JSPS Core-to-Core Program, A. Advanced Research Networks, and partly supported by grants-in-aid for scientific research from the Japanese Ministry of Health, Labor, and Welfare.

patients with Stevens-Johnson syndrome. Ophthalmology. (2007) 114:1294302. doi: 10.1016/j.ophtha.2006.10.029

11. Sotozono C, Ueta M, Koizumi N, Inatomi T, Shirakata Y, Ikezawa Z, et al. Diagnosis and treatment of Stevens-Johnson syndrome and toxic epidermal necrolysis with ocular complications. Ophthalmology. (2009) 116:685-90. doi: 10.1016/j.ophtha.2008.12.048

12. Mockenhaupt M, Viboud C, Dunant A, Naldi L, Halevy S, Bouwes Bavinck JN, et al. Stevens-Johnson syndrome and toxic epidermal necrolysis: assessment of medication risks with emphasis on recently marketed drugs. the EuroSCARstudy. J Invest Dermatol. (2008) 128:35-44. doi: 10.1038/sj.jid.5701033

13. Yamane Y, Aihara M, Ikezawa Z. Analysis of Stevens-Johnson syndrome and toxic epidermal necrolysis in Japan from 2000 to 2006. Allergol Int. (2007) 56:419-25. doi: 10.2332/allergolint.O-07-483

14. Chung WH, Hung SI, Hong HS, Hsih MS, Yang LC, Ho HC, et al. Medical genetics: a marker for Stevens-Johnson syndrome. Nature. (2004) 428:486. doi: $10.1038 / 428486 \mathrm{a}$

15. Ozeki T, Mushiroda T, Yowang A, Takahashi A, Kubo M, Shirakata Y, et al. Genome-wide association study identifies HLA-A*3101 allele as a genetic risk factor for carbamazepine-induced cutaneous adverse drug reactions in Japanese population. Hum Mol Genet. (2011) 20:1034-41. doi: $10.1093 / \mathrm{hmg} / \mathrm{ddq} 537$

16. McCormack M, Alfirevic A, Bourgeois S, Farrell JJ, Kasperaviciute D, Carrington $M$, et al. HLA-A*3101 and carbamazepine-induced hypersensitivity reactions in Europeans. N Engl J Med. (2011) 364:1134-43. doi: 10.1056/NEJMoa1013297

17. Mockenhaupt M, Wang CW, Hung SI, Sekula P, Schmidt AH, Pan RY, et al. HLA-B* 57:01 confers genetic susceptibility to carbamazepine-induced SJS/TEN in Europeans. Allergy. (2019) 74:2227-30. doi: 10.1111/all.13821

18. Hung SI, Chung WH, Liou LB, Chu CC, Lin M, Huang HP, et al. HLA-B*5801 allele as a genetic marker for severe cutaneous adverse reactions caused by allopurinol. Proc Natl Acad Sci USA. (2005) 102:4134-9. doi: 10.1073/pnas.0409500102

19. Lonjou C, Borot N, Sekula P, Ledger N, Thomas L, Halevy S, et al. A European study of HLA-B in Stevens-Johnson syndrome and toxic epidermal necrolysis related to five high-risk drugs. Pharmacogenet Genomics. (2008) 18:99-107. doi: 10.1097/FPC.0b013e3282f3ef9c

20. Tohkin M, Kaniwa N, Saito Y, Sugiyama E, Kurose K, Nishikawa J, et al. A whole-genome association study of major determinants for allopurinolrelated Stevens-Johnson syndrome and toxic epidermal necrolysis in Japanese patients. Pharmacogenomics J. (2013) 13:60-9. doi: 10.1038/tpj.2011.41 
21. Kaniwa N, Saito Y, Aihara M, Matsunaga K, Tohkin M, Kurose K, et al. HLA-B locus in Japanese patients with anti-epileptics and allopurinol-related StevensJohnson syndrome and toxic epidermal necrolysis. Pharmacogenomics. (2008) 9:1617-22. doi: 10.2217/14622416.9.11.1617

22. Lee HS, Ueta M, Kim MK, Seo KY, Sotozono C, Kinoshita S, et al. Analysis of ocular manifestation and genetic association of allopurinol-induced StevensJohnson syndrome and toxic epidermal necrolysis in South Korea. Cornea. (2016) 35:199-204. doi: 10.1097/ICO.0000000000000708

23. Ueta M. Results of detailed investigations into stevens-johnson syndrome with severe ocular complications. Invest Ophthalmol Vis Sci. (2018) 59:DES183-91. doi: 10.1167/iovs.17-23537

24. Wakamatsu TH, Ueta M, Tokunaga K, Okada Y, Loureiro RR, Costa KA, et al. Human leukocyte antigen class I genes associated with StevensJohnson syndrome and severe ocular complications following use of cold medicine in a Brazilian population. JAMA Ophthalmol. (2017) 135:355-60. doi: 10.1001/jamaophthalmol.2017.0074

25. Jongkhajornpong P, Lekhanont K, Pisuchpen P, Chantaren P, Puangsricharern V, Prabhasawat P, et al. Association between HLA-B*44:03-HLA-C*07:01 haplotype and cold medicine-related Stevens-Johnson syndrome with severe ocular complications in Thailand. Br J Ophthalmol. (2018) 102:1303-7. doi: 10.1136/bjophthalmol-2017-311823

26. Ma KS, Chung WH, Hsueh YJ, Chen SY, Tokunaga K, Kinoshita S, et al. Human leucocyte antigen association of patients with Stevens-Johnson syndrome/toxic epidermal necrolysis with severe ocular complications in Han Chinese. Br J Ophthalmol. (2021). doi: 10.1136/bjophthalmol-2020-317105. [Epub ahead of print].

27. Lee HK, Yoon KC, Seo KY, Ueta M, Kim MK. Chronic ocular complications of Stevens-Johnson syndrome associated with causative medications in Korea. $J$ Allergy Clin Immunol Pract. (2017) 6:700-2.e2. doi: 10.1016/j.jaip.2017.09.001

28. Ueta M, Sotozono C, Inatomi T, Kojima K, Hamuro J, Kinoshita S. Association of IL4R polymorphisms with Stevens-Johnson syndrome. J Allergy Clin Immunol. (2007) 120:1457-9. doi: 10.1016/j.jaci.2007.07.048

29. Ueta M. Genetic predisposition to stevens-johnson syndrome with severe ocular surface complications. Cornea. (2015) 34(Suppl. 11):S158-65. doi: 10.1097/ICO.0000000000000605

30. Ueta M, Nakamura R, Saito Y, Tokunaga K, Sotozono C, Yabe T, et al. Association of HLA class I and II gene polymorphisms with acetaminophen-related Stevens-Johnson syndrome with severe ocular complications in Japanese individuals. Hum Genome Var. (2019) 6:50. doi: 10.1038/s41439-019-0082-6

31. Jun I, Rim JH, Kim MK, Yoon KC, Joo CK, Kinoshita S, et al. Association of human antigen class I genes with cold medicine-related Stevens-Johnson syndrome with severe ocular complications in a Korean population. $\mathrm{Br} J$ Ophthalmol. (2019) 103:573-6. doi: 10.1136/bjophthalmol-2018-313263

32. Wakamatsu TH, Ueta M, Inoue C, Costa KA, Sakano LY, Sallum JMF, et al. Human leukocyte antigen class I and II genes associated with dipyrone-related Stevens-Johnson syndrome and severe ocular complications in a Brazilian population. Ocul Surf. (2021) 20:173-5. doi: 10.1016/j.jtos.2021.02.008

33. Kannabiran C, Ueta M, Sangwan V, Rathi V, Basu S, Tokunaga K, et al. Association of human leukocyte antigen class 1 genes with Stevens Johnson syndrome with severe ocular complications in an Indian population. Sci Rep. (2017) 7:15960. doi: 10.1038/s41598-017-15965-7

34. Jongkhajornpong P, Ueta M, Lekhanont K, Puangsricharern V, Prabhasawat P, Chantaren P, et al. Association of HLA polymorphisms and acetaminophenrelated Steven-Johnson syndrome with severe ocular complications in Thai population. Br J Ophthalmol. (2020). doi: 10.1136/bjophthalmol-2020-317315. [Epub ahead of print].

35. Ueta M. Cold medicine-related Stevens-Johnson syndrome/toxic epidermal necrolysis with severe ocular complications-phenotypes and genetic predispositions. Taiwan J Ophthalmol. (2016) 6:108-18. doi: 10.1016/j.tjo.2016.06.001

36. Sudo T, Kamikawaji N, Kimura A, Date Y, Savoie CJ, Nakashima H, et al. Differences in MHC class I self peptide repertoires among HLA-A2 subtypes. J Immunol. (1995) 155:4749-56.

37. Harr T, French LE. Stevens-Johnson syndrome and toxic epidermal necrolysis. Chem Immunol Allergy. (2012) 97:149-66. doi: 10.1159/0003 35627

38. Wen SH, Lai MJ, Yang KL. Human leukocyte antigen-A, -B, and -DRB1 haplotypes of cord blood units in the Tzu Chi Taiwan cord blood bank. Hum Immunol. (2008) 69:430-6. doi: 10.1016/j.humimm.2008.05.012

39. Butt GF, Hassan A, Wallace GR, Kinoshita S, Ahmad S, Ueta M, et al. Human leukocyte antigen B*0702 is protective against ocular StevensJohnson syndrome/toxic epidermal necrolysis in the UK population. Sci Rep. (2021) 11:2928. doi: 10.1038/s41598-021-82400-3

40. Ueta M. Stevens-Johnson syndrome/toxic epidermal necrolysis with severe ocular complications. Expert Rev Clin Immunol. (2020) 16:285-91. doi: 10.1080/1744666X.2020.1729128

41. Honda T, Matsuoka T, Ueta M, Kabashima K, Miyachi Y, Narumiya S. Prostaglandin $\mathrm{E}(2)-\mathrm{EP}(3)$ signaling suppresses skin inflammation in murine contact hypersensitivity. J Allergy Clin Immunol. (2009) 124:809-18 e2. doi: 10.1016/j.jaci.2009.04.029

42. Kunikata T, Yamane H, Segi E, Matsuoka T, Sugimoto Y, Tanaka S, et al. Suppression of allergic inflammation by the prostaglandin E receptor subtype EP3. Nat Immunol. (2005) 6:524-31. doi: 10.1038/ni1188

43. Ueta M, Matsuoka T, Narumiya S, Kinoshita S. Prostaglandin E receptor subtype EP3 in conjunctival epithelium regulates late-phase reaction of experimental allergic conjunctivitis. J Allergy Clin Immunol. (2009) 123:46671. doi: 10.1016/j.jaci.2008.09.044

44. Chantaren P, Jongkhajornpong P, Ueta M, Puangsricharern V, Lekhanont $\mathrm{K}$, Pisuchpen P, et al. Association of IKZF1 SNPs in cold medicine-related Stevens-Johnson syndrome in Thailand. Clin Transl Allergy. (2019) 9:61. doi: 10.1186/s13601-019-0300-9

45. Ueta M, Hamuro J, Nishigaki H, Nakamura N, Shinomiya K, Mizushima $\mathrm{K}$, et al. Mucocutaneous inflammation in the Ikaros Family Zinc Finger 1keratin 5-specific transgenic mice. Allergy. (2018) 73:395-404. doi: 10.1111/all. 13308

46. Ueta M, Tokunaga K, Sotozono C, Sawai H, Yoon KC, Kim MK, et al. HLA$\mathrm{A}^{*}$ 02:06 and PTGER3 polymorphism exerts additive effects in cold medicinerelated Stevens-Johnson syndrome with severe ocular complications. Hum Genome Variat. (2015) 2:15023. doi: 10.1038/hgv.2015.23

Conflict of Interest: The author declares that the research was conducted in the absence of any commercial or financial relationships that could be construed as a potential conflict of interest.

Publisher's Note: All claims expressed in this article are solely those of the authors and do not necessarily represent those of their affiliated organizations, or those of the publisher, the editors and the reviewers. Any product that may be evaluated in this article, or claim that may be made by its manufacturer, is not guaranteed or endorsed by the publisher.

Copyright (c) 2021 Ueta. This is an open-access article distributed under the terms of the Creative Commons Attribution License (CC BY). The use, distribution or reproduction in other forums is permitted, provided the original author(s) and the copyright owner(s) are credited and that the original publication in this journal is cited, in accordance with accepted academic practice. No use, distribution or reproduction is permitted which does not comply with these terms. 